\title{
"PASSEI PELA ESCOLA E CONSEGUI CHEGAR À UNIVERSIDADE!": AS TRAJETÓRIAS DE VIDA E FORMAÇÃO NARRADAS POR JOVENS UNIVERSITÁRIOS
}

\author{
"I PASSED THROUGH SCHOOL AND WAS ABLE TO GET TO UNIVERSITY!": \\ LIFE AND EDUCATIONAL PATHS NARRATED BY UNIVERSITY STUDENTS
}

\section{"¡PASÉ POR LA ESCUELA Y CONSEGUÍ LLEGAR A LA UNIVERSIDAD!”: LAS TRAYECTORIAS DE VIDA Y FORMACIÓN POR JÓVENES UNIVERSITARIOS}

\section{Resumo:}

O presente texto tem como objetivo analisar as marcas das culturas escolares na trajetória de formação dos estudantes universitários de diferentes cursos superiores. Trata-se do recorte de uma pesquisa de doutorado, de abordagem qualitativa, pautada nos estudos sobre culturas escolares, trajetórias de formação e inserção no ensino superior. A produção de dados foi realizada a partir de entrevistas narrativas e encontros do grupo de discussão. As trajetórias narradas foram textualizadas em mônadas, na perspectiva de Walter Benjamin, constituindo narrativas de vida e de formação. O texto apresenta a análise de quatro mônadas, apontando marcas relativas às culturas escolares nessas trajetórias, como relações interpessoais e vínculos de amizade estabelecidos no contexto escolar, dentre outros, revelando os diferentes sentidos que a escola produziu nas histórias desses jovens.

Palavras-chave: Jovens universitários. Narrativas de vida e de formação. Culturas escolares. Inserção no ensino superior.

\section{Abstract:}

This paper aims to analyze the traces of school cultures in the trajectory of formation of university students from different courses. It is part of a doctoral research study of school cultures, development paths, and attainment of higher education. The data was based on narrative interviews and discussion group meetings. The narrative trajectories were contextualized into monads, according to the approach of Walter Benjamin, constituting life and development narratives. The paper analyses four monads, pointing to traces of school cultures in these trajectories, such as interpersonal relationships and ties of friendship established in the school context, among others, revealing the different meanings that the school produces in the stories of these youth.

Keywords: University students. Life and development narratives. School cultures. Attainment of higher education.

\section{RESUMEN:}

El presente texto tiene como objetivo analizar las marcas de las culturas escolares en las trayectorias de formación de jóvenes universitarios de diferentes cursos superiores. Se trata del recorte de una investigación de doctorado, con enfoque cualitativo, basada en los estudios sobre culturas escolares, trayectorias de formación e inclusión en la enseñanza superior. La producción de datos fue realizada a partir de entrevistas narrativas y encuentros del grupo de discusión. Las trayectorias narradas fueron transcritas en mónadas, en la perspectiva de Walter Benjamin, constituyendo narrativas de vida y de formación. El texto presenta el análisis de cuatro mónadas, indicando marcas relativas a las culturas escolares en esas trayectorias, como las relaciones interpersonales y vínculos de amistad establecidos en el contexto escolar, entre otros, revelando los diferentes sentidos que la escuela produjo en las historias de esos jóvenes.

\footnotetext{
${ }^{1}$ Doutora em Educação - Universidade São Francisco (USF) - Bragança Paulista, SP - Brasil. Professora Titular Universidade São Francisco(USF) -, Bragança Paulista, SP - Brasil. E-mail: brenatta@gmail.com Submetido em: 02/05/2017- Aceito em: 15/03/2018
}

(C) ETD-Educação Temática Digital Campinas, SP $\quad$ v.20 $\quad$ n.3 $\quad$ p. 741-760 jul./set. 2018 
aqui apresentado centra-se nas marcas das culturas escolares narradas por estudantes universitários. O texto está organizado em quatro seções: inicialmente apresentamos os aportes teóricos que nortearam a pesquisa; em seguida, o contexto de sua realização; a análise dos dados; e nossas considerações finais.

\section{A JUVENTUDE: TRAJETÓRIA DE FORMAÇÃO E INSERÇÃO NO ENSINO SUPERIOR}

A trajetória de formação, para alguns jovens, não termina com a saída do ensino médio; muitos pleiteiam o ensino superior e, não o conseguindo de imediato, considerando suas necessidades econômicas, pressões sociais, familiares, bem como a busca pessoal pela formação específica, partem para a formação técnica e profissional.

Olhar para as trajetórias de formação desses estudantes universitários é compreender seu processo de inserção no ensino superior como continuidade da sua trajetória, levando em consideração, em razão de circunstâncias da própria trajetória, percorreram caminhos de entrada na universidade privada. Alguns ingressam no curso que fazia parte de seus sonhos, optam por aqueles cujas condições foram favoráveis: localização, valor de mensalidade, obtenção de bolsa, etc. Nesse caso, poderá haver ou não sua identificação com o curso escolhido e, consequentemente, com a profissão.

Em virtude das distintas condições econômicas e socioculturais dos estudantes, há diferenças consideráveis entre eles, no que diz respeito à inserção no ensino superior caracterizando o contexto universitário como lugar profícuo para o aprofundamento de questões que envolvem jovens estudantes, a partir da investigação das vivências e experiências no processo de continuidade de sua formação, corroborando o que afirma Carrano (2009, p. 181): "Apesar da existência de estudos sobre o tema, ainda sabemos muito pouco sobre as trajetórias escolares e biográficas dos estudantes universitários". A ampliação de pesquisas que busquem perceber o jovem estudante, sua condição como sujeito cultural e político que vivencia o contexto universitário e que já possui uma trajetória de estudos e de busca pela formação, se faz necessária para identificar quem são esses jovens que, por meios distintos, adentram no ensino superior.

Inseridos em um quadro social marcado por profundas desigualdades, alguns jovens brasileiros se encontram em condições que contrastam profundamente com a de outras pessoas da sua idade, cujas trajetórias de formação se mostram diferentes, com determinantes diversos para a continuidade dos estudos.

A inserção de jovens, principalmente aqueles das classes sociais mais pobres, no ensino superior em instituições privadas é determinada pela expansão da escolaridade, que configurou outro perfil dos que estão chegando à universidade, oriundos de diversos 
quadros sociais, com trajetórias de formação distintas. Muitos deles só conseguem essa inserção por conta das políticas públicas, como o FIES² e o Prouni ${ }^{3}$.

Zago (2006, p. 226) aponta que o prolongamento da escolaridade entre jovens vem sendo estudado nas duas últimas décadas no campo da sociologia da educação, e estudos produzidos no Brasil e no exterior vêm fornecendo indicadores teóricos importantes para problematizar o que tem sido chamado de "Iongevidade escolar", "casos atípicos" ou "trajetórias excepcionais" de jovens pobres, que sempre tiveram a escolaridade de curta duração. Parte dessa produção define-se na linha de investigação que busca explicações sobre os processos que possibilitaram aos jovens romper com a tradição frequente no seu meio de origem e compor trajetórias de êxito escolar.

O financiamento dos estudos, de moradia, transporte, alimentação, saúde, trabalho, cultura e lazer aparece como elemento-chave na complexa condição do estudante universitário para a continuação de seus estudos, pois todos esses aspectos demandam custos que representam pesos relevantes no orçamento mensal desses sujeitos (ZAGO, 2006). Para que o estudante possa seguir sua formação, há entraves constantes, como carga horária de trabalho, tempo insuficiente para dar conta das solicitações do curso e outros, de ordem social e cultural, condicionados pelos baixos recursos financeiros. Além disso, é possível observar também diferentes dimensões de êxito e de fracasso na trajetória de formação, como reflexo e efeito cumulativo da escolarização anterior (GRIGNON; GRUEL, 1999 apud ZAGO, 2006).

Apesar dessas ponderações, ao considerarmos a família, o incentivo dos pais, a condição de moradia - morar em residência alugada ou própria -, questões de transporte, a viabilidade de permanência, podemos vislumbrar maiores possibilidades de acesso e inserção no ensino superior, como a ampliação de vagas, a expansão das universidades públicas e o fortalecimento das instituições privadas.

Para Zago (2006, p.230), os antecedentes escolares são outro ponto a ser considerado nesse quadro: "A desigualdade de oportunidades de acesso ao ensino superior é construída de forma contínua e durante toda a história escolar dos candidatos". E o autor afirma, ainda, que

\footnotetext{
${ }^{2}$ O Fundo de Financiamento Estudantil (Fies) é um programa do Ministério da Educação destinado a financiar prioritariamente estudantes de cursos de graduação (Informações disponíveis em: http://portal.mec.gov.br/.Acesso em: 13 jan. 2015).

3 O Programa Universidade para Todos (ProUni) é um programa do Ministério da Educação, criado pelo Governo Federal em 2004, que concede bolsas de estudo integrais e parciais (50\%) em instituições privadas de ensino superior, em cursos de graduação e sequenciais de formação específica, a estudantes brasileiros, sem diploma de nível superior (Informações disponíveis em: <www.siteprouni.mec.gov.br>. Acesso em: 13 jan. 2015).
} 
número de vagas disponíveis para matrícula e o desafio do vestibular corresponde a um processo que permeia a trajetória de formação dos jovens brasileiros, principalmente os das camadas populares, que veem na universidade a possibilidade de continuidade educacional e de ascensão social. Pelas histórias de vida de jovens estudantes universitários, é possível compreender os caminhos percorridos para a inserção no ensino superior, considerando as contingências de suas trajetórias de formação, a inserção na universidade e, especialmente, as marcas na trajetória de formação, no que se refere às culturas e às disciplinas escolares.

Tais marcas não são apagadas com a entrada na universidade - ao contrário, elas são reafirmadas, realçadas e ressignificadas pelos jovens universitários, à medida que se deparam com as vicissitudes da vida universitária. Portanto, cabe a indagação: Quais as marcas da cultura escolar que os jovens trazem na memória na trajetória de formação? 0 que eles narram sobre a escola? Esse é o foco do presente texto. Apresentaremos na sequência os procedimentos da pesquisa.

\section{O CONTEXTO DA PESQUISA}

Os participantes da pesquisa foram dez jovens universitários (dois homens e oito mulheres) dos cursos de Farmácia, Enfermagem, Fisioterapia, Pedagogia, Administração e Ciências Contábeis de uma universidade confessional do interior do estado de São Paulo. Para o recorte aqui apresentado analisamos as narrativas de quatro desses depoentes, dos quais fazemos uma breve apresentação: Stéfthanny tem 21 anos e cursa Farmácia; Sabrino tem 23 anos e é estudante de Enfermagem; Priscila, com 26 anos, cursa Pedagogia; e Laís, que tem 20 anos e cursa Fisioterapia.

A pesquisa, de abordagem qualitativa, aproxima-se dos estudos biográficos na educação, tendo como instrumentos metodológicos as entrevistas narrativas e a audiogravação de grupos de discussão, cujos encontros geraram narrativas orais. Ela teve como objetivo conhecer as trajetórias de formação de jovens estudantes universitários e os caminhos trilhados para inserção no ensino superior. Como objetivos específicos para este texto, visamos analisar as marcas das culturas escolares na trajetória de formação dos estudantes universitários.

A pesquisadora, primeira autora deste texto, na condição de professora da instituição que atuou nesses diferentes cursos, fez o convite coletivo a todos os ex-alunos, e dez deles aceitaram participar. Com cada um desses sujeitos foram realizadas duas entrevistas narrativas, as quais foram transcritas, devolvidas aos participantes e aprovadas por eles. Além das entrevistas, esses jovens foram convidados para um encontro coletivo, para discutirmos algumas questões que emergiram das histórias narradas. Por contingências de horário, foram organizados dois grupos e realizamos um encontro com cada grupo. As narrativas orais presentes nas entrevistas e nas transcrições dos encontros foram textualizadas na forma de mônadas, na perspectiva benjaminiana. As mônadas são

$\begin{array}{llllll}\text { (C) ETD- Educação Temática Digital } & \text { Campinas, SP } & \text { v.20 } & \text { n.3 } & \text { p.741-760 } & \text { jul./set. } 2018\end{array}$ 
pequenas crônicas originárias das narrativas dos sujeitos, como apontam Rosa e Ramos (2008, p. 572): "Numa perspectiva benjaminiana, mônadas são pequenas crônicas que guardam consigo fragmentos de histórias, mas que, juntas, exibem a capacidade de dar sentido a um contexto maior". Para as autoras, no campo da pesquisa, "trabalhar com mônadas potencializa, do ponto de vista metodológico, a produção de um espectro de significados" (p. 569). A escolha metodológica definiu a apresentação das narrativas de vida e de formação dos estudantes nos capítulos específicos de análise.

$\mathrm{Na}$ elaboração dessas mônadas procuramos tecer uma história com as trajetórias narradas pelos estudantes. As mônadas das trajetórias dos quatro estudantes selecionados para este texto foram analisadas considerando os estudos pautados nas marcas e nas representações das culturas escolares.

\section{AS MARCAS DAS CULTURAS ESCOLARES NAS TRAJETÓRIAS DE JOVENS UNIVERSITÁRIOS}

$\mathrm{Na}$ construção de algumas das narrativas de vida de jovens universitários sobre a trajetória de formação sobressaíram as experiências no contexto da escola, bem como as marcas evidenciadas nessa trajetória, dentre elas aquelas referentes às disciplinas, aos estudos, aos professores e aos pares.

Nas leituras dessas narrativas de vida fomos encontrando pontos de convergência e de divergência entre elas, buscando olhar para as singularidades, em um movimento de entrelaçamento das falas que constituem a tecedura deste texto. Nas narrativas de vida dos estudantes universitários sobre o contexto escolar, o que emerge é sua reflexão sobre o vivenciado por eles, com destaque para a escola e as culturas escolares. Os relatos deixaram explícita a configuração de uma escola idealizada, a qual não foi vivenciada plenamente; destacaram as experiências vividas e os encontros e desencontros desses jovens nessas trajetórias escolares; e permitiram aprofundar o entendimento das experiências vividas no contexto escolar e, pelo trajeto trilhado por eles até a sua inserção na universidade, possibilitaram compreender as culturas escolares existentes e sua importância para os jovens.

A análise das culturas escolares presentes no universo escolar desses jovens universitários pode ser ampliada, no tocante à forma como são constituídas, aos símbolos de que se valem e aos dispositivos a partir dos quais se constroem. Viñao Frago e Escolano (2001, p.61, grifos do autor), ao tratarem da dimensão espacial dos estabelecimentos de ensino e da dimensão educativa do espaço escolar para além dos mobiliários, tratam dos espaços e sua arquitetura na dimensão de lugar. Para eles, "levado espaço ao lugar é, pois, uma construção. $O$ espaço se projeta ou se imagina; o lugar se constrói. Constrói-se 'a partir do fluir da vida' e a partir do espaço como suporte". A escola também é uma construção cultural, implicando várias questões a serem analisadas.

$\begin{array}{llllll}\text { (C) ETD- Educação Temática Digital } & \text { Campinas, SP } & \text { v.20 } & \text { n.3 } & \text { p.741-760 } & \text { jul./set. } 2018\end{array}$ 
Selecionamos as narrativas de vida e de formação de Stéfthanny e Sabrino, por identificarmos experiências significativas na vivência escolar: para Stéfthanny houve marcas que a obrigaram a certas atitudes para conviver na escola e, para Sabrino, ao contrário, houve oportunidade de ascensão social e mudança de vida na trajetória de formação. Procuramos não fragmentar as mônadas construídas no texto original, sem deixar escapar os sentidos produzidos pelos depoentes.

\section{Passei pela escola e consegui chegar à universidade!}

Eu sempre fui boa aluna, sempre me dediquei muito, desde cedo, pois comecei a falar e a ler muito cedo, mesmo antes de ir para a escola. Sinto que tive uma boa educação; meus professores sempre gostaram de mim, pois sempre fui muito estudiosa, porém mudei muito de escola, porque eu tive alguns problemas nas escolas por onde passei. Eu sofri o que é considerado hoje como bullying nas escolas, quando era mais nova, por isso mudei muito de escola.

Eu nunca gostei de ir para a escola, eu gostava de estudar e os professores sempre me incentivavam, porque acredito que viam um futuro em mim, não sei por quê. Eu comecei a ler cedo, eu lia em casa sozinha, pegava livros de primos, lia e fazia conta sozinha e sempre gostei de brincar de escolinha, desde cinco anos de idade.

Mais tarde minha mãe me colocou na pré-escola, foi tranquilo! E depois me colocou no ensino fundamental, aí foi mais difícil. Na verdade, eu gostava muito de estudar, ler os livros, das lições, mas não gostava de ir para a escola, e então eu tinha muita falta, mas sempre tirei nota boa, mas eu faltava muito e até achava que iria sentir um pouco de defasagem nisso, mas eu me empenhava e conseguia passar bem em todas as matérias. Agora, no ensino médio foi difícil, foi uma das piores fases da minha vida, no primeiro e no segundo colegial eu estava meio perdida, todo mundo fica perdido, não sabe o que fazer, não sabe o que quer, mas eu sempre estudei muito e tive professores excelente que me mostraram um mundo amplo, isso me ajudou a concluir os estudos. No terceiro colegial, estudava na escola, fazia cursinho pré-vestibular e me sobrecarreguei demais, e foi muita, muita loucura, mas consegui passar com notas boas em ambos os cursos.

Eu sempre fui meio cheinha e os colegas me chamavam de gorda, baleia e me excluíam das brincadeiras, dos trabalhos e eu sofria muito com isso, sempre sofri com isso. Antes de mudar de escola eu mudava muito de sala, porque tinha sempre um colega ou outro que mexia muito comigo e me perseguia, então eu fazia o intervalo sozinha e às vezes meus pais eram chamados para me acompanhar ou me levar embora da escola, pois eu começava a chorar e não tinha condição. Nos primeiros anos do ensino fundamental, na primeira e segunda série tinha uma pessoa que me perseguia na escola, me ameaçava e eu tinha muito medo, as faltas eram frequentes e assim foi até o ensino médio. Mudei várias vezes de escola e fui até ameaçada de morte por uma colega que dizia que eu era puxa-saco dos professores, por isso tirava notas altas.

Minha mãe me levou no psicólogo quando eu estava na sexta-série e, com a ajuda dele, consegui ir até o ensino médio e terminar. 
Não foi fácil não, foi difícil, porque eu não sei, o meu jeito não agradava muito as pessoas, tinha muita gente que não gostava de mim, era muito difícil ir para a escola, eu me sentia mal, eu tive poucos amigos, muito poucos, alguns ficaram para sempre, mas eu tive muito poucos amigos e eu me sentia mal, não foi fácil, foi muito difícil, acho que por isso eu me empenhava na escola, para dar um sobressalto, chamar a atenção de alguma forma e me destacar de alguma forma.

Eu não sou atleta, não canto, não fazia nada de diferente, mas acho que estudar foi o jeito de me destacar na escola, mas foi muito difícil, pois a escola, apesar de ser um ambiente que a gente tem que sentir bem, eu nunca me senti bem na escola, eu não gostava de ir para a escola, apesar de ter professores legais e de eu gostar de ficar perto deles, eu não gostava, nossa, foi difícil, eu sofri muito com a convivência com os colegas, talvez por ser mais tímida, era mais na minha e não gostava de conversar.

Muitas vezes eu ficava calada o dia inteiro não sabia me comunicar com as pessoas, eu era muito tímida, ficava nervosa, calada, os livros eram o único caminho para conhecer $e$ entender o mundo, principalmente, no primeiro $e$ segundo colegial. No primeiro colegial foi uma turbulência de coisas, aconteceram várias coisas ruins, com os colegas, sofria a cada ruptura, a cada mudança, não era agradável para mim. O que mais me marcou no colegial, tirando os professores, foram as poucas amizades que eu fiz, foi o que me motivava, às vezes, para ir para a escola. As comemorações, festinhas, eu não gostava muito, mas eu ia, mesmo tendo dificuldades, eu tinha consciência que tinha que passar por essa fase, eu tinha consciência e consegui, passei pela escola e consegui chegar à universidade.

Escolhi cursar Farmácia no terceiro colegial, na verdade eu sempre quis fazer faculdade, já mudei várias vezes de curso, eu quis fazer Psicologia, quis fazer Fisioterapia, queria cuidar de crianças, depois eu quis fazer o curso de Química, quis fazer Biomedicina também, tudo ligado à química, sempre ligado à área da saúde, e escolhi Farmácia no terceiro colegial, foi assim, na reta final, com pouco tempo para decidir, no começo eu não sabia se ia ser legal, eu me interessei por causa da química. Eu imaginei que mexeria muito com essa parte, então escolhi Farmácia, com a orientação da professora de química; ela falou que seria interessante. (Stéfthanny, estudante do Curso de Farmácia - Entrevista, maio 2012) 


\section{Foi sensacional!}

Sempre estudei em escola pública, comecei cedo, acho que com 5 anos. Passei por três escolas diferentes. Como moro em um sítio, fiz o prezinho, e da primeira à quarta série nas escolas do bairro. Fui para o bairro vizinho para fazer da quinta à oitava série, e, do primeiro ao terceiro ano colegial, fui para o centro de Bragança para fazer o ensino médio. Foi uma trajetória bem gostosa. A parte mais gostosa foi o ensino médio, com certeza. Porque ali você aprende realmente o que você quer e sabe o que você gosta. Fiz novos amigos, ganhei uma cultura bem diferente das outras escolas, foi sensacional.

Para começar, nunca pensei em estudar numa escola grande, que foi o EMABA, em Bragança. Imagina um garoto de sítio chegar à cidade... A maior galera, que eu nunca tinha visto na vida. No começo foi difícil a adaptação, mas com o passar do tempo fui conhecendo novos amigos, os professores foram me conhecendo. De repente, a escola inteira me conhecia. Eu não era popular, mas todo mundo me conhecia. Me extrovertia, estudava também, uma parte bacana. Me divertia muito! Além de estudar, me diverti e conheci novas pessoas. Penso que a escola, no ensino médio, deveria oferecer um curso de qualificação profissional, para aluno ter uma noção mais real do que ele tem que fazer depois do ensino médio, se ele vai querer frequentar uma universidade ou não, o que ele desejaria que acontecesse.

Então, terminei o ensino médio em 2005, com 17 anos. Prestei vestibular para Medicina Veterinária na FESB. Passei em último, mas passei. Só que era um curso muito caro e não me senti preparado. Depois do ensino médio fui fazer um cursinho pré-vestibular no Colégio Santo Agostinho, em três anos e meio. Depois, surgiu uma oportunidade de fazer um curso técnico em Enfermagem, no Centro Paula Souza, em Atibaia. Pensei: "acho que vou conhecer, para ver se é disso que eu gosto e se é isso que eu quero". Foram dois anos difíceis, mas foi bem bacana. Foi lá que descobri que o que eu quero, realmente, é isso: ser técnico em Enfermagem e depois frequentar a universidade, para ser um futuro enfermeiro. (Sabrino, estudante do Curso de Enfermagem - Entrevista maio 2012)

Como podemos perceber nas narrativas de vida e de formação de Stéfthanny e Sabrino, para cada um, o lugar considerado escola teve um significado diferente, permeado de elementos oriundos de suas percepções do que foi a escola vivenciada por ambos. Para Stéfthanny, a escola trouxe marcas que remetem a lembranças de sofrimento, bullying, isolamento, dentre outras situações embaraçosas que marcaram sua trajetória escolar, apontando para um desencantamento com esse espaço, ao assinalar:

Sinto que tive uma boa educação, meus professores sempre gostaram de mim, pois sempre fui muito estudiosa, porém mudei muito de escola, porque eu tive alguns problemas nas escolas por onde passei. Eu sofri o que é considerado hoje como bullying nas escolas, quando era mais nova, por isso mudei muito de escola.

A narrativa de vida de Sabrino evidencia as diferenças entre um e outro contexto escolar vivenciado, indicando que, ao ir para o ensino médio em uma escola no centro da 
cidade, no contexto urbano, experimentou outra realidade que não aquela das escolas da zona rural:

Sempre estudei em escola pública, comecei cedo, acho que com 5 anos. Passei por três escolas diferentes. Como moro em um sítio, fiz o prezinho, e da primeira à quarta série nas escolas do bairro. Fui para o bairro vizinho para fazer da quinta à oitava série, e, do primeiro ao terceiro ano colegial, fui para o centro de Bragança para fazer o ensino médio. Foi uma trajetória bem gostosa. A parte mais gostosa foi o ensino médio, com certeza. Porque ali você aprende realmente o que você quer e sabe o que você gosta. Fiz novos amigos, ganhei uma cultura bem diferente das outras escolas, foi sensacional.

A escola caracteriza-se por ser um espaço e lugar demarcado internamente pela divisão do tempo, do trabalho, das tarefas cumpridas, da vigilância e do controle, o que implica ser ela um lugar e espaço com características próprias, constituída através do tempo e da história por meio de vários elementos: sociais, políticos, econômicos e culturais (VIÑAO FRAGO; ESCOLANO, 2001).

Sabrino relata a adaptação necessária em um contexto escolar diferente daquele que conhecia, sendo sua trajetória marcada por espaços diferenciados, definindo a dimensão da escola vivenciada no campo e na cidade e sua experiência com outros colegas e professores e, principalmente, com o contexto urbano:

Para começar, nunca pensei em estudar numa escola grande, que foi o EMABA, aqui em Bragança. Imagina um garoto de sítio chegar à cidade... A maior galera, eu nunca tinha visto na vida. No começo foi difícil a adaptação, mas com o passar do tempo fui conhecendo novos amigos, os professores foram me conhecendo.

Entretanto, pensar nesses elementos presentes nas narrativas de vida e de formação é pensar na cultura escolar ou em culturas escolares. Pensar sobre o espaço escolar, a tecnologia nele presente, a arquitetura da escola, os materiais, a disciplina do tempo, os cursos estruturados em seriação, as práticas escolares, a inter-relação entre os saberes, os procedimentos e seus símbolos, que diferem de uma escola para outra, requer necessária sensibilidade para perceber e entender as complexas relações que vão se estabelecendo entre os sujeitos que as compõem. Embora elementos das culturas escolares estejam presentes nas escolas todas, cada uma é singular, tem sua própria cultura. Isso se evidenciou na narrativa de Sabrino, quando ele fala de sua escola no ensino médio: "Fiz novos amigos, ganhei uma cultura bem diferente das outras escolas".

A escola constitui-se pelos processos nela vividos, e os espaços que compõem a escola atual, o modo como foram sendo formados, seus objetivos e a forma como foram sendo significados, transformando-se em lugares escolares, elucidam as concepções pelas quais a cultura escolar ou as culturas escolares corroboram o entendimento e a formação de suas personagens - professores, estudantes, jovens, crianças, diretores, bem como tantos outros profissionais. 
A escola possui regras disciplinadoras que compõem o seu espaço, e as personagens que vivenciam essas particularidades transformam-na em lugar, a partir de suas experiências. Para Stéfthanny, vivenciar a escola representou um esforço de adaptação às regras e aos posicionamentos exigidos, como ela relata: "Eu não sou atleta, não canto, não fazia nada de diferente, mas acho que estudar foi o jeito de me destacar na escola, mas foi muito difícil, pois a escola, apesar de ser um ambiente que a gente tem que sentir bem, eu nunca me senti bem na escola".

Perrenoud (1995) indaga sobre o ofício do aluno, enfatizando que o contexto escolar é formado por um jogo arquitetado com regras a serem cumpridas, e o aluno desde cedo aprende a se movimentar dentro desse jogo. O autor chama atenção para o fato de que todo jogo também tem suas "regras burladas", ou seja, há outras significações para a vivência do aluno na escola, que fogem dos dispositivos impostos pela própria escola e ganham outros sentidos.

Stéfthanny, em sua trajetória de formação, burlou diversas vezes para fugir dos dispositivos de controle da escola, encontrando outros sentidos para a sua vivência escolar, como ela discorre:

Mais tarde minha mãe me colocou na pré-escola, foi tranquilo. E depois me colocou no ensino fundamental, aí foi mais difícil. Na verdade, eu gostava muito de estudar, ler os livros, das lições, mas não gostava de ir para a escola, então eu tinha muita falta, mas sempre tirei nota boa, mas eu faltava muito e até achava que iria sentir um pouco de defasagem nisso, mas eu me empenhava e conseguia passar bem em todas as matérias.

Conseguir ser aprovada em todas as disciplinas escolares, apesar das frequentes faltas, denota que Stéfthanny burlou diversas vezes regras internas e preestabelecidas da escola, no acompanhamento das aulas, nas lições, na frequência escolar, evidenciando, em sua narrativa, a turbulência de sua trajetória escolar. Ela foi contundente, ao afirmar que "passou" pela escola, o que Ihe atribuiu experiências marcantes no seu trajeto como estudante.

As relações estabelecidas dentro da escola configuraram experiências significativas nesse contexto: desenharam qual escola foi vivenciada, na dialética entre escola e aluno e denotaram, por vezes, vivências positivas. E para outros estudantes os processos vivenciados no contexto escolar foram marcados por experiências de dor, sofrimento, ausência, abandono, o que configurou estratégias de sobrevivência para o cumprimento de tarefas e etapas na trajetória escolar.

A trajetória de Stéfthanny sinaliza para as estratégias e os esforços acumulados para concluir os estudos: 
No primeiro colegial foi uma turbulência de coisas, aconteceram várias coisas assim, com os colegas, sofria a cada ruptura, a cada mudança, não era agradável para mim. O que mais me marcou no colegial, tirando os professores, foram as poucas amizades que eu fiz, foi o que me motivava às vezes para ir para a escola. As comemorações, festinhas, eu não gostava muito, mas eu ia, mesmo tendo dificuldades, eu tinha consciência que tinha que passar por essa fase, eu tinha consciência e consegui, passei pela escola e consegui chegar à universidade.

A necessidade da permanência na escola requer, de fato, a formulação de estratégias que "garantam a sobrevivência e uma certa tranquilidade" (PERRENOUD, 1995, p. 17). O autor conclui: "o exercício intensivo do ofício de aluno pode também produzir efeitos perversos: trabalhar só para a nota, construir uma relação utilitarista com o saber, com o trabalho, com o outro" (p.17), promovendo experiências a partir de mecanismos de sobrevivência. Ou, ainda, muitos permanecem na escola por necessidade, mesmo que tenham que circular por diferentes escolas, por diferentes espaços e lugares. Ou, ainda, lugares de constituição da identidade. Priscila e Laís têm o que nos dizer sobre isso:

\section{Uma festinha de despedida!}

Eu comecei fazendo educação infantil, a pré-escola, na cidade de São Carlos, e a lembrança que eu tenho desse período foi bem marcante, pois eu fui sempre muito insegura, eu chorava muito, a minha adaptação foi terrível e eu sempre fui muito apegada à minha mãe; nessa época não sei bem por que, quem fez a minha adaptação na escola foi meu pai. Eu sentia menos segurança ainda e depois o tempo foi passando e gostei da pré-escola. Lembro a primeira vez que eu levei para casa a folhinha da tarefa de casa que eu tinha que copiar a letrinha $A$; lembro que eu me senti importante escrevendo uma letra, depois, na primeira série já começou a ser um pouquinho mais difícil, a insegurança permaneceu. Sempre morei na zona rural, com o deslocamento de casa até a escola eu sofria muito, pois era uma hora, uma hora e meia de ônibus e essa insegurança eu depositava na minha irmã, eu grudava nela e de braço dado, ela tinha que me levar até à porta da sala.

Na primeira série minha mãe tinha que me levar e buscar e a professora começou a reclamar, pois perdia o ônibus porque tinha que esperar comigo pela minha mãe. Eu não tinha prazer de ir para a escola. Na segunda série, um fato que me marcou muito foi que uma aluna da minha sala iria mudar para São Paulo, e eu também iria mudar para Salto de Pirapora, próximo a Sorocaba, mas para essa menina, que ia mudar para São Paulo uma semana antes, a professora fez uma festinha de despedida e para mim não, e essa foi uma situação que me marcou muito.

Uma coisa que ia ficando muito clara é que não tive nenhuma relação de afeto e de afinidade com os meus professores, não sei se por ter essa ligação muito forte com a minha mãe, eu sempre estava na escola, mas querendo a minha mãe, eu não tive esse vínculo e não lembro de nenhum professor ter tido comigo. Outra dificuldade que tive depois que eu me mudei para essa cidade é que eu não conseguia ficar mais de dois anos em uma escola, então eu fiz o pré em uma escola, a primeira série e a segunda série em São Carlos e fui terminar a segunda série em Salto de Pirapora.

Na nova cidade achei a escola mais acolhedora, meus pais estavam vivendo uma fase diferente, mais tranquila, então eu consegui aproveitar melhor. Foi fácil a adaptação nessa escola, mas coincidiu com uma reorganização nacional das

(C) ETD-Educação Temática Digital Campinas, SP $\quad$ v.20 n.3 $\quad$ p. 741-760 jul./set. 2018 
escolas: como em tal escola ficara somente educação infantil, tal escola da primeira a quinta série, então, novamente, eu tive que mudar de espaço, e o que marcou para mim foi a questão da afinidade com os professores, eu via minhas amigas cumprimentando a professora do ano anterior e eu não tinha esse registro.

O que eu gostava muito, a partir da terceira e quarta série, era participar dos eventos da escola. Tinha desfile, eu estava lá, tinha dancinha, eu estava lá, tinha que recitar poeminha, eu também adorava. Essa parte social da escola eu gostava muito e eu sei que isso é em função de eu morar em sítio, pois eu nunca tive vizinhos, assim, a escola para mim era o lugar para eu me realizar, eu fazia muitos amigos. Eu dificilmente voltava para casa depois do almoço, sempre ia para a casa de alguém para aproveitar aquele momento.

Eu terminei a quarta série e a situação financeira dos meus pais estava um pouco melhor, então eles decidiram colocar meus irmãos mais velhos em uma escola particular, seria com bastante esforço, pois a escola ficava na cidade vizinha de Sorocaba. Então colocaram meus irmãos no colégio Salesiano e eu continuei na escola pública, mas eles ficaram com dó de mim e fizeram mais uma forcinha. Não conseguiram me colocar na mesma escola que meus irmãos e me colocaram no colégio Adventista. Infelizmente eles me colocaram no Adventista, então "trocou seis por meia dúzia". Nessa época do Adventista, o que ficou marcado foram os professores muito bravos. Os professores de ciências eram quase um mito na escola. Eles passavam sem dar bom dia para ninguém, um absurdo. A professora de história, então! Um dia, não fiz a lição de casa, e enquanto ela ia tomando as respostas dos outros, fiz rapidinho com medo dela. Na aula de inglês, um dia a professora fez uma pergunta para mim, já na sétima série, eu quase fiz xixi na calça porque não sabia o que eu tinha que responder. A escola foi sempre marcada por esse medo.

Até que, a partir da oitava série, mudei de escola novamente, fui para o Objetivo, lá em Sorocaba mesmo; então consegui me realizar, porque da oitava série até o terceiro ano do ensino médio eu consegui permanecer na mesma escola. Só que hoje vejo minha dificuldade, a partir do momento em que me mudei para escola particular, com todo o esforço dos meus pais, eu não me sentia pertencente àquele ambiente. Em função da diferença social mesmo; então isso foi uma coisa que ficou muito marcada nesse período de escola, desde o começo até o terceiro ano do ensino médio.

(Priscila, estudante do Curso de Pedagogia - Entrevista, maio 2012)

\section{Uma história de vida!}

Na infância, não cursei a educação infantil integral, fiz só três meses de prezinho na época. Depois entrei direto no SESI, e foi minha história de vida inteira desde o pré até o ensino médio. Era um sonho estudar no SESI, e minha mãe conseguiu a vaga para mim. Quando entrei, foi muita felicidade, sempre foi meu sonho o SESI.

Na minha época não tinha ensino médio no SESI. No ano em que fui para o ensino médio eles conseguiram abrir uma turma. Fui da primeira turma do ensino médio do SESI em Bragança; isso é muito gratificante, porque foram onze anos de SESI, uma história de vida mesmo.

Como foi a primeira escola e, praticamente, a única onde cursei ensino fundamental e médio, foi algo bem significativo e que ficou marcado em minha vida, porque foi lá que aprendi tanto a educação básica para mim quanto princípios também, dentro da escola. Foi uma escola que me formou 100\%, sou grata até hoje a todos os professores. Até os professores que deram aula para mim

(C) ETD-Educação Temática Digital Campinas, SP $\quad$ v.20 n.3 $\quad$ p. 741-760 jul./set. 2018 
quando eu tinha sete anos, até hoje se lembram de mim, foi um fato bem marcante, mesmo, na minha vida.

Minha turma foi muito pequena, porque foi a primeira turma do SESI. Então, eram 13 estudantes só na sala, e a gente viveu uma relação como se fosse uma família, como se fôssemos irmãos. Os professores eram muitos bons, porque estavam preocupados com a nossa carreira profissional. Então, toda atividade que era realizada na sala de aula, a maioria era focada já na carreira profissional. Tudo o que nós fazíamos era focado nisso.

Até cheguei a fazer um TCC já no SESI. Realizamos um projeto chamado "Amigos da natureza". Teve uma banca também, veio um pessoal de fora para examinar nosso projeto. Para ajudar no projeto veio um vereador da cidade para ajudar, outras autoridades, então isso ficou marcado, porque no ensino médio é difícil ter isso em outras escolas. Isso me marcou muito, esse projeto e o TCC, porque já trouxe essa bagagem do ensino médio para a USF, e a gente não tem tanta dificuldade assim, porque já sabe mais ou menos como funciona.

Escolhi cursar Fisioterapia no período do ensino médio. O meu sonho nunca foi Fisioterapia. Minha mãe sempre falou que eu ia fazer Fisioterapia e eu falava que não, porque não gostava muito de Fisioterapia. la prestar vestibular para Odontologia, mas desisti. Para Medicina também era impossivel porque não tinha condições de pagar. Minha pontuação no vestibular quando eu fiz até dava, porque passei em primeiro lugar na universidade em Fisioterapia. Só que não tinha condições financeiras.

Comecei a visitar a universidade e pesquisar sobre o curso, fazer visitas na clínica e conversar com os estudantes, e fui vendo que aquela era minha área. Fui me adaptando e me encontrei em Fisioterapia, e é um curso que hoje não largo por nada, amo mesmo de paixão o que eu faço.

(Laís, estudante do Curso de Fisioterapia - Entrevista, maio 2012)

Nessas duas narrativas de vida aqui apresentadas é perceptível como para cada estudante, ao acessar a memória do tempo escolar, há um movimento diferenciado, que esbarra nas contingências da vida pessoal e familiar, delineando, individualmente, um trajeto que nos faz entender que esses jovens não vivenciaram a mesma escola, como instituição com as marcas de seu tempo.

Outro aspecto importante é perceber por quais meios o espaço escolar se delineia, tornando-se lugar, e para além dele, estabelecem-se também na escola as relações sociais, de amizade e os vínculos. Priscila, em sua narrativa de vida sobre a trajetória escolar, menciona:

O que eu gostava muito a partir da terceira e quarta série era participar dos eventos da escola. Tinha desfile, eu estava lá, tinha dancinha, eu estava lá, tinha que recitar poeminha, eu também adorava. Essa parte social da escola eu gostava muito e eu sei que isso é em função de eu morar em sítio, pois eu nunca tive vizinhos, assim a escola para mim era o lugar para eu me realizar, eu fazia muitos amigos. Eu dificilmente voltava para casa depois do almoço, sempre ia para a casa de alguém para aproveitar aquele momento. 
Tal narrativa remete à afirmação de Viñao Frago e Escolano (2001, p. 31, grifos do autor): " 'a primeira escola é a vida' e os locais em que ela se instala estarão abertos ao ar e ao sol", entendendo que o lugar da escola, da aprendizagem, do coletivo está para além do espaço escolar: é um lugar para estreitar laços de amizade e partilhar outras experiências. Nesse sentido, a escola é lugar de socialização para estudantes, embora também possa promover a exclusão de alguns, pela sua posição social.

Priscila igualmente tece considerações sobre problemas de adaptação de uma escola para outra, quando relata:

a partir do momento em que me mudei para a escola particular, com todo o esforço dos meus pais, eu não me sentia pertencente àquele ambiente. Em função da diferença social mesmo, então isso foi uma coisa que ficou muito marcada nesse período de escola, desde o começo até o terceiro ano do ensino médio.

É necessário que a escola assegure a "igualdade individual de oportunidades" para os estudantes, no que se refere à sua formação escolar, afirma Dubet (2008, p. 14), ao questionar o que seria uma escola justa. Para o autor, "Seria também necessário acrescentar informações sobre os atores e sobre sua capacidade de circular e se mobilizar, rompendo com algumas das formas mais banais da hipocrisia escolar, das quais os mais fracos são vítimas" (p. 12). Afirma ainda Dubet (2008, p. 12-13) que os mais fracos "não dominam as sutilezas dos jogos hierárquicos entre os estabelecimentos" e "as sutilezas das orientações, todas essas pequenas diferenças que acabam por fazer as grandes diferenças".

Ao serem indagados e instigados a falar sobre as lembranças da escola, principalmente no período do ensino médio, tempo de verificação das possibilidades de continuação dos estudos, todas as narrativas citam as relações e os vínculos de amizade, sinalizando as influências de professores e da escola nesse processo, como a orientação vocacional e a formação para o vestibular.

Laís, em vários trechos de seu relato, menciona:

Como foi a primeira escola e, praticamente, a única onde cursei ensino fundamental e médio, foi algo bem significativo e que ficou marcado em minha vida, porque foi lá que aprendi tanto a educação básica quanto princípios, também, dentro da escola. [...]

Então, toda atividade que era realizada na sala de aula, a maioria era focada já na carreira profissional. Tudo o que nós fazíamos era focado nisso.

Para muitos estudantes, a escolarização é um período de amadurecimento, de saber posicionar-se diante das condições da escola. Perrenoud (1995, p. 21) afirma que "o ofício do aluno" é "definido essencialmente pelo futuro que ele prepara e a escola faz como que se esse futuro bastasse para conferir sentido ao trabalho de cada dia", e, em vários 
momentos nas narrativas de vida e de formação, os jovens desta pesquisa atribuem à trajetória escolar seu fracasso ou sucesso, lugar de preparação para o futuro.

Esses depoimentos nos reportam a Delory-Momberger (2008, p. 87), quando afirma:

À individualização dos percursos e à subjetivação da atividade profissional, à concepção de competência compreendida como conjunto indissociável de qualificações profissionais e qualidades pessoais, responde uma biografização da formação que se traduz pelo reconhecimento progressivo do capital de saberes e de saber fazer, acumulado ao longo da experiência e pela contextualização das ações de formação nos itinerários individuais.

É com as experiências na escola que os estudantes, cada um de uma forma, a partir de seu itinerário individual, estabelecem um repertório próprio que vai delineando suas escolhas pessoais e profissionais. Delory-Momberger (2008, p. 110) indica ainda que, se "os percursos de formação são estruturados pelos quadros sociais e institucionais nos quais se desenvolvem e se eles são modelizados pelas representações coletivas ${ }^{4}$ que os sujeitos incorporam", eles se inscrevem também em "biografias" que "extraem, precisamente, sua singularidade de um jogo único de inter-relações entre modelos sociais e experiências individuais". Pensar nas experiências escolares desses estudantes é pensar nos significados que eles destinam a elas e na forma como significam o espaço em lugar. Lugar de boas lembranças, lugar de solidão, lugar de novos caminhos, lugar de formação e segurança, lugar transitório, como sinalizam Vinão Frago e Escolano (2001).

Entretanto, tais lugares para esses jovens foram construídos a partir de experiências postas no fluxo da vida pessoal, familiar e estudantil, no zigue-zague das relações, das escolhas alheias, do trajeto realizado a meio fio, considerando as potencialidades psicológicas, mentais, emocionais, culturais, físicas, de aprendizagem, além da interface com os dispositivos legais, políticos, sociais e econômicos, pelos quais o fio da trajetória escolar se fez. Viñao Frago e Escolano (2001, p. 26) apontam, ainda, que "o espaço escolar tem de ser analisado como um constructo cultural que expressa e reflete, para além de sua materialidade", sendo ele "um mediador cultural em relação à gênese e formação dos primeiros esquemas cognitivos e motores, ou seja, um elemento significativo do currículo, uma fonte de experiência e aprendizagem".

Priscila, ao se lembrar de uma das escolas por qual passou, relata:

\footnotetext{
${ }^{4} \mathrm{~A}$ autora não explicita seu entendimento sobre "representações coletivas", mas tal conceito remete-nos às ideias de Roger Chartier, no âmbito da história cultural. Para ele, as representações coletivas constituem matrizes de práticas construtoras do próprio mundo social. Trata-se de um conceito relacional, pois implica prática e ação. Elas são construídas em campos de dominação e disputa, portanto, marcadas por relações de poder; "não são de forma alguma discursos neutros: produzem estratégias e práticas (sociais, escolares, políticas) que tendem a impor uma autoridade à custa de outros, por elas menosprezados, a legitimar um projecto reformador ou a justificar, para os próprios indivíduos, as suas escolhas e condutas" (CHARTIER, 1990, p. 17).
}

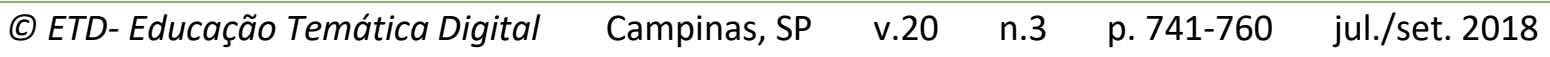


Foi fácil a adaptação nessa escola, mas coincidiu com uma reorganização nacional das escolas; como em tal escola ficará somente educação infantil, tal escola da primeira a quinta série, então, novamente, eu tive que mudar de espaço, e o que marcou para mim foi a questão da afinidade com os professores, eu via minhas amigas cumprimentando a professora do ano anterior e eu não tinha esse registro.

Como nos lembram Vinão Frago e Escolano (2001, p. 63):

O conhecimento de si mesmo, a história interior, a memória, em suma, é um depósito de imagens. De imagens de espaços que, para nós, foram, alguma vez e durante algum tempo, lugares. Lugares nos quais algo de nós ali ficou e que, portanto, nos pertencem; que são, portanto, nossa história.

As análises dessas narrativas de vida e formação levam-nos a concluir que a escola se constitui como lugar social, cultural, de aprendizagens através dos significados atribuídos pelos sujeitos. Nas narrativas dos estudantes universitários ficou evidente que a escola possui múltiplos significados, no que se refere ao lugar presente no tempo da infância e da juventude, pois, para o mesmo sujeito, esse lugar pode mudar e passar a ter diferentes conotações. Para alguns estudantes, a escola significou lugar de isolamento, solidão, desafios para conseguirem se adequar às regras, à convivência; para outros, representou a formação de uma vida; a mudança de uma escola para outra foi redenção, a oportunidade de fazer novos amigos.

Contudo, para os jovens autores das narrativas de vida e de formação aqui apresentadas, a escola possui lugares construídos em sua memória que estão na contramão da linearidade subentendida para as trajetórias escolares, nos mostrando que os processos da inserção e da permanência na escola devem ser vistos através de lentes caleidoscópicas, para o entendimento da dimensão multifacetada que engloba a escola e seus contextos.

\section{CONSIDERAÇÕES FINAIS}

Para a síntese deste capítulo cabe a pergunta: O que fica das lembranças das culturas escolares para os estudantes universitários?

Nas análises das narrativas de vida e formação apresentadas, o que fica são marcas relativas aos laços de amizade feitos entre pares no decorrer da trajetória de formação, às experiências vividas de aceitação e acolhimento, bem como de isolamento e discriminação. Isso confirma posições, como as de Perrenoud (1995), de que a escola é também espaço de socialização de crianças, adolescentes e jovens. Espaços que, para muitos, se tornam lugares de convivência afetiva. Para alguns, espaços justos, como considera Dubet (2008). De qualquer forma, a escola fez a diferença - positiva ou negativa - nas vidas desses estudantes.

Pensar nas lembranças da escola é pensar em um tempo de descobertas, de convívio e de estreitamento de laços de amizades. Muitos estudantes narram os amigos feitos na 
escola que até hoje fazem parte de sua história de vida. A escola aparece também como lugar de formação da própria identidade a partir dos desafios impostos aos estudantes.

Tais desafios comportam a superação de se desvincular do núcleo familiar, quando o estudante passa a conviver com pessoas e espaços diferentes daqueles habituais; a escola passa a ter significado como lugar na vida desses estudantes, a partir das experiências nela vivenciadas, como apontam Viñao Frago e Escolano (2001). As experiências compreendem, muitas vezes, momentos de dor, desamparo, em que têm que enfrentar o desconhecido; outras vezes, as experiências resultam prazerosas e cobertas de boas lembranças.

Em relação aos professores, importa ressaltar que o papel desempenhado por eles é de suma importância na formação dos estudantes. As narrativas apontam a função do professor na preparação para o vestibular, no ensino médio, e o quanto a aprendizagem das disciplinas específicas se mostra um desafio na trajetória de formação desses estudantes.

Eles realçaram em suas lembranças as marcas sofridas devido ao sistema educacional, pois por muitas vezes tiveram o processo de ensino e de aprendizagem interrompido pelas mudanças constantes de professores e pelas variações nos métodos de ensino. Narraram também as marcas deixadas pelas classificações dadas pelo sistema escolar e, consequentemente, pelos professores, com as repetências, a postura rígida dos professores e a classificação subjetiva dada àqueles que não têm o sucesso escolar esperado, como aponta Dubet (2008).

Os jovens relataram por diversas vezes as estratégias de resistência e subversão às regras e normas estabelecidas pela escola para garantir a sobrevivência na escola, burlandoas quando necessário. Por outro lado, muitos estudantes sinalizaram a postura humana do professor, atrelada ao incentivo e ao acolhimento recebidos desses profissionais no decorrer da trajetória, entendendo a relação professor-aluno como uma via de mão dupla, com responsabilidades de ambos os lados, porém ressaltando que os professores fizeram toda a diferença na sua trajetória de formação e em sua história de vida.

As narrativas denotam também sentimentos como medo, dificuldade, aversão, e também o inverso: prazer e facilidade em aprender matemática, apontando para representações dúbias no que se refere às marcas da matemática escolar, em que as experiências são múltiplas e singulares nas trajetórias de formação.

As lembranças da escola e de professores sinalizam as marcas e os direcionamentos relativos à trajetória de formação dos estudantes universitários, marcas que os acompanharam no processo de inserção no ensino superior e os acompanham na formação universitária. 


\section{REFERÊNCIAS}

BENJAMIN Walter. O Colecionar. In: BOLLE, Wille (Org.). Passagens. São Paulo: IMESP, 2006. p. 237-246.

BERTAUX, Daniel. Narrativas de vida: a pesquisa e seus métodos. Natal: EDUFRN; São Paulo: Paulus, 2010.

BOSI, Ecléa. Memória e sociedade: lembranças de velhos. 3. ed. São Paulo: Companhia das Letras, 1994.

CARRANO, Paulo. Jovens universitários: acesso, formação, experiências e inserção profissional. In: PONTES, Marília (Coord.). Estado da Arte sobre juventude na pósgraduação brasileira: educação, ciências sociais e serviço social (1999-2006). Belo Horizonte: Argvmentvm, 2009. v. 1, p. 179-228.

CHARTIER, Roger. A história cultural: entre práticas e representações. Tradução Maria Manuela Galhardo. Lisboa: Difel, 1990.

DELORY-MOMBERGER, Christine. Biografia e educação: figuras do indivíduo-projeto. Natal: UFRN; São Paulo: Paulus, 2008.

DUBET, François. $\mathbf{O}$ que é uma escola justa?: a escola das oportunidades. Trad. Ione Ribeiro Valle. São Paulo: Cortez, 2008.

PERRENOUD, Philippe. Ofício de aluno e sentido do trabalho escolar. Porto: Porto, 1995.

ROSA, Maria Inês P.; RAMOS, Tacita A. Memórias e odores: experiências curriculares na formação docente. Revista Brasileira de Educação, v. 13, n. 39, p. 565-599, set./dez. 2008.

SCHÜTZE, Fritz. Pesquisa biográfica e entrevista narrativa. In: WELLER, W.; PFAFF, N. (Org.). Metodologias da pesquisa qualitativa em Educação. Petrópolis, RJ: Vozes, 2010. p. 210222.

VIÑAO FRAGO, Antonio; ESCOLANO, Agustín. Currículo, espaço e subjetividade. 2. ed. Rio de Janeiro: DP\&A, 2001.

ZAGO, Nadir. Do acesso à permanência no ensino superior: percursos de estudantes universitários de camadas populares. Revista Brasileira de Educação, Belo Horizonte, v. 11, n. 32, p. 226-237, maio/ago. 2006.

\footnotetext{
' Revisão gramatical de responsabilidade da autora
} 